\title{
Molecular mapping of quantitative trait loci for drought tolerance in maize plants
}

\author{
H. Rahman ${ }^{1,2}$, S. Pekic ${ }^{1,4}$, V. Lazic-Jancic ${ }^{3}$, S.A. Quarrie ${ }^{1,5}$, S.M.A. Shah ${ }^{2}$, \\ A. Pervez ${ }^{6}$ and M.M. Shah ${ }^{6}$ \\ 'John Innes Centre, Norwich Research Park, Colney, Norwich \\ ${ }^{2}$ Department of Plant Breeding and Genetics, \\ NWFP Agricultural University Peshawar, Pakistan \\ ${ }^{3}$ Maize Research Institute, Zemun Polje, Belgrade-Zemun, Serbia \\ ${ }^{4}$ Faculty of Agriculture, Belgrade University, Belgrade-Zemun, Serbia \\ ${ }^{5}$ School of Biology, Newcastle University, Newcastle-upon-Tyne, UK \\ ${ }^{6}$ Biotechnology Program, Department of Environmental Sciences, \\ Commission on Science and Technology for Sustainable Development in the South, \\ Institute of Information Technology, Abbottabad, Pakistan \\ Corresponding author: M.M. Shah \\ E-mail: mmshah@ciit.net.pk
}

Genet. Mol. Res. 10 (2): 889-901 (2011)

Received November 4, 2010

Accepted January 18, 2011

Published May 17, 2011

DOI 10.4238/vol10-2gmr1139

\begin{abstract}
Drought tolerance is one of the most important but complex traits of crops. We looked for quantitative trait loci (QTLs) that affect drought tolerance in maize. Two maize inbreds and their advanced lines were evaluated for drought-related traits. A genetic linkage map developed using RFLP markers was used to identify QTLs associated with drought-related traits. Twenty-two QTLs were detected, with a minimum of one and a maximum of nine for drought-related traits. A single-QTL was detected for sugar concentration accounting for about $52.2 \%$ of the phenotypic variation on chromosome 6 . A single-QTL was also identified for each of the traits root density, root dry weight, total biomass, relative water content, and leaf abscisic acid content, on chromosomes 1 and 7 , contributing to $24,0.2,0.4,7$, and $19 \%$ of the phenotypic variance, respectively. Three QTLs were identified for grain yield on chromosomes
\end{abstract}


1,5 , and 9 , explaining $75 \%$ of the observed phenotypic variability, whereas four QTLs were detected for osmotic potential on chromosomes 1,3 , and 9 , together accounting for $50 \%$ of the phenotypic variance. Nine QTLs were detected for leaf surface area on chromosomes 3 and 9, with various degrees of phenotypic variance, ranging from 25.8 to $42.2 \%$. Four major clusters of QTLs were identified on chromosomes 1, 3, 7, and 9. A QTL for yield on chromosome 1 was found co-locating with the QTLs for root traits, total biomass, and osmotic potential in a region of about $15 \mathrm{cM}$. A cluster of QTLs for leaf surface area were coincident with a QTL for osmotic potential on chromosome 3. The QTLs for leaf area also clustered on chromosome 9, whereas QTLs for leaf abscisic acid content and relative water content coincided on chromosome 7, 10 $\mathrm{cM}$ apart. Co-location of QTLs for different traits indicates potential pleiotropism or tight linkage, which may be useful for indirect selection in maize improvement for drought tolerance.

Key words: Drought tolerance; Genetic variation; Linkage maps; Molecular markers; Quantitative trait loci; Zea mays

\section{INTRODUCTION}

Maize (Zea mays L.) belongs to the family Poaceae and has a great agronomic and economic importance around the globe. The plant has a well-characterized genetic system with a haploid chromosome set of 10 . Overall improvement in maize is primarily based on a hybrid breeding system. The maize plant is particularly sensitive to drought at reproductive and developmental stages, and breeding to improve water stress tolerance has been a challenge. The potential of drought tolerance for crop species is dependent on a repertoire of constitutively and adaptively expressed characteristics usually interrelated with one another. These characteristics may include increased levels of abscisic acid (L-ABA) in leaves and other organs of the plant, rooting behavior and osmotic adjustment. L-ABA is considered as the hormonal trait most universally affected by moisture deficit regimes (Hartung and Davies, 1991). Several studies in cereals have indicated that increased L-ABA levels observed during drought onset play a significant role in the adaptive response of plants to decreased moisture availability (Quarrie, 1991). In addition to directing the expression of genes involved in desiccation tolerance, L-ABA has a central role in conserving water in the plant. This is achieved by reducing the amount of water loss during transpiration.

Maize, a cross-pollinated species with a comparatively small genome, is amenable to gene investigation, offering researchers the opportunity to study the location and behavior of factors underlying quantitative genetic variation. A number of quantitative traits have been extensively investigated using conventional biometrical approaches (Hallauer and Miranda, 1989). The development of mapping techniques in the last few decades has opened novel avenues for the identification of chromosomal regions harboring quantitative trait loci (QTLs) controlling important traits. Studies have indicated that genes for specific traits such as drought tolerance (Agrama and Moussa, 1996; Ajmone et al., 1996; Ribaut et al., 1997; Austin and Lee, 1998; Frova et al., 1999; Sari-Gorla et al., 1999; Kebede et al., 2001; Li et al., 2002; Babu et al., 
2003; Tuberosa et al., 2003) can be reliably identified using these newly developed molecular mapping techniques (Edwards et al., 1987). With the development of molecular techniques, it is now possible to estimate the relative effect of a particular QTL on a certain trait and to compare the mapping position of QTLs with that of mutants and/or cDNA clones of known function (Paterson et al., 1988; Shah et al., 1999; Tuberosa et al., 2002a; Xiao et al., 2005; Yang et al., 2007; Kuraparthy et al., 2007; Qiu et al., 2007). This information provides important clues regarding probable genes underlying the investigated trait (Paterson et al., 1988).

The production and productivity of major crops depend largely upon the availability of a balanced genetic and environmental system. There are, however, several challenges and serious problems posed especially by abiotic factors. These may include shortage of water resources, climate warming, and unimproved agricultural practices. Drought and salinity are the two most important abiotic factors that cause tremendous loss to crop yield throughout the world. Maize is also highly sensitive to water stress, which may be more pronounced at specific physiological stages of plant growth. Drought stress during flowering time results in increased length of the anthesis-silking interval, which causes severe loss of yield (Li et al., 2002). Conventional breeding programs and efforts in drought tolerance depend to a large extent on field trials of populations and progeny, and the accuracy in phenotypic scoring for this trait in the field is usually laborious and difficult (Ribaut et al., 1997). Molecular marker-based mapping and selection, which can allow breeders to distinguish genotypes directly for the presence and absence of traits, may be a better approach to develop drought-tolerant germplasm in maize.

The purpose of this study was to ascertain the genomic position, number and magnitude of QTLs affecting genetic variation for a number of physiological traits at the whole plant level, in $\mathrm{F}_{2: 3}$ families derived from a cross between two maize inbreds showing contrasting expression for some drought-related parameters. The information thus obtained provides valuable information on the feasibility of using QTLs for drought tolerance in a marker-assisted selection scheme to improve drought resistance in maize.

\section{MATERIAL AND METHODS}

The experimental material comprised two inbred parents, DTP79 and B73, and a population of $\mathrm{F}_{2: 3}$ families derived from the cross between DTP79 and B73 (subsequently referred to as DTP population). DTP79 is a line extracted from the original drought-tolerant population (DTP) of the CIMMYT maize program, selected on the basis of yield under drought conditions in Zambia. B73 is a North-American commercial inbred that is known to be drought susceptible.

\section{Drainpipe drought experiment}

A drainpipe drought experiment was carried out with $105 \mathrm{~F}_{2: 3}$ families. Drainpipes, 15 $\mathrm{cm}$ in diameter and $75 \mathrm{~cm}$ long, were split into two halves longitudinally, joined with heavy-duty tape, and closed with a heavy-gauge plastic sheet at one end; they were then filled with $21.3 \mathrm{~kg}$ of modified John Innes No. 2 compost with a moisture content of $6.8 \%$. Prior to planting, $2.0 \mathrm{~L}$ water was added to each pipe in several increments to allow uniform water distribution and to prevent leakage. Six seeds of each genotype were placed on the wet soil with embryo up, in two batches of three seeds planted on consecutive days. Greenhouse temperature was maintained at $25 / 15^{\circ} \mathrm{C}$, with a 16 -h photoperiod and $80 \%$ relative humidity. One week after planting when 
seedlings had emerged in all pipes, they were thinned to four plants per drainpipe, attempting to retain four similar plants. Additional aliquots of $0.50 \mathrm{~L}$ water were added to each drainpipe after $14,21,27$, and 35 days. This watering regime gave a gradual development of drought stress.

Ten days after planting when the 2 nd leaf was fully expanded in most plants, growth measurements were started on each plant. This included the maximum plant length (length from the soil surface to the tip of the longest leaf) on alternate days and the maximum length and width of the latest fully expanded leaf. These growth measurements were continued until the experiment was terminated and plants were sampled for various parameters. When stress symptoms were visible, plants were scored for a visible drought score based on a 1-4 scale, i.e., 1) all four plants dark green and fully turgid, 2) plants light green with soft leaves, 3) plants greyish green with soft leaves, and 4) plants with grey-green leaves and rolled.

\section{Drainpipe physiological parameters}

When most of the plants showed the 6th leaf fully expanded and were about $50-60 \mathrm{~cm}$ in length (45 days after planting), the experiment was terminated. Two plants were sampled from each pipe on the first day, and the remaining two were sampled the following day. The youngest fully expanded leaf was sampled for relative water content, osmotic potential and leaf ABA concentration. For osmotic potential, $8 \times 1-\mathrm{cm}$ leaf discs were sampled, stored on ice and transferred to $-70^{\circ} \mathrm{C}$ until analysis. After thawing for $20 \mathrm{~min}$, cell sap was expressed from the leaf discs using a screw press and its solute concentration measured with a freezing point depression osmometer (Roebling Camlab, Cambridge, UK). Osmotic potentials (OP) were calculated using the relationship: $\mathrm{OP}=$ cRT, where $c$ is the solute concentration $(\mathrm{mM}), R$ is the gas constant and $T$ the absolute temperature of the leaf when sampled, assumed to be $300{ }^{\circ} \mathrm{K}$. For L-ABA determination, leaf samples were freeze-dried and powdered in a reciprocating ball mill (Glen Creston, Middlesex, UK), and an aliquot was extracted with water at $40^{\circ} \mathrm{C}$ overnight. L-ABA concentration was measured by radioimmunoassay with a monoclonal antibody specific for (S)-L-ABA-free acid (Quarrie et al., 1988), as described by Lebreton et al. (1995). The samples for sugar analysis were prepared as a fine powder after freeze-drying the excised embryos of the maize kernel of each sample. Sugar contents were determined in powdered samples of $50 \mathrm{mg}$ dry weight as described by Singletary and Below (1990). Sugar was extracted three times using $80 \%(\mathrm{v} / \mathrm{v})$ ethanol at $60^{\circ} \mathrm{C}$, and the supernatant was evaporated to dryness. The pellet was dissolved in 1 to $3 \mathrm{~mL}$ water, with sonication and thorough mixing (Zinselmeier et al., 1999). An aliquot was removed from the samples, which were incubated at $55^{\circ} \mathrm{C}$ for $2 \mathrm{~h}$. Sugar was quantified in triplicate according to the method of Nelson (1944). The leaf surface area (LA) of parental and the recombinant inbred lines was measured according to Thompson and Leyton (1971) by sampling 4 plants from each genotype.

\section{Drainpipe root parameters}

Plants were cut at the sub-coleoptilar node; shoots were weighed and transferred to an oven at $70^{\circ} \mathrm{C}$ for dry weight determination. For root distribution and density, the two halves of each drainpipe were carefully separated to avoid disturbing the root distribution, and the soil core divided into four zones of $18 \mathrm{~cm}$ each. Based on the visual root distribution in zone 1 (near the surface), 2, 3, and 4 (at the base), a score of 1-4 was established: 1) root pattern dense and restricted to zone one, 2) roots less dense but extending to zone two; 3 ) roots dense and 
extending to zone three, and 4) root distribution extending to zone four. Root masses collected from zones 1 and 2 and zones 3 and 4 were kept separate for dry weight measurement. The roots collected were cleaned from the compost using a sieve, washed carefully and oven-dried at $80^{\circ} \mathrm{C}$ for $72 \mathrm{~h}$. Samples from each of the four zones of the soil core were collected, weighed and oven-dried at $80^{\circ} \mathrm{C}$ for $72 \mathrm{~h}$. The difference between the soil pre- and post-drying weights was used to calculate the $\%$ moisture level at sampling time.

\section{Yield trials}

Two parents and $105 \mathrm{~F}_{2: 3}$ DTP plants were tested in a Cernozem soil at the Maize Research Institute, Serbia. Four seeds were planted per hill spaced $30 \mathrm{~cm}$ apart and with $80 \mathrm{~cm}$ between rows. A single row of each family was sown with 11 hills per row, and a guard row at each end of the plot, which was rainfed. Plants were thinned to two per hill after seedling establishment and grown with standard agricultural practices to maturity. The season was relatively dry during flowering time and early grain filling, so plants were assessed visually for drought response during early grain filling on two occasions 10 days apart. Ears were collected at maturity and yield per ear was assessed at constant kernel moisture.

\section{RFLP analysis}

Leaves were sampled from $105 \mathrm{~F}_{2: 3}$ DTP plants and the two parents. DNA extraction was carried out using a modified CTAB method as described by Murray and Thompson (1980). Purified DNA was resuspended in $1 \mathrm{X}$ TE buffer. DNA fragments were separated by $0.8 \%$ agarose gel electrophoresis and transferred overnight by capillary action onto charged nylon membrane (Hybond $\mathrm{N}$-Amersham International) in $0.4 \mathrm{M} \mathrm{NaOH}$, using Southern blot procedures. After Southern blotting, membranes were rinsed in $2 \mathrm{X} \mathrm{SSC}$, air dried and stored at $4^{\circ} \mathrm{C}$. Pre-hybridization, hybridization and washing were performed as described by Sharp et al. (1988). Membranes were hybridized with cDNA probes for maize from the University of Missouri-Columbia and California State University, USA (UMC and CSU). Probes were labeled with ${ }^{32} \mathrm{P}(\mathrm{dCTP})$ and were then exposed to autoradiographic film at $-80^{\circ} \mathrm{C}$ for 3-6 days. The X-ray films were developed in a dark room and banding patterns for the parents and segregating population were scored.

\section{Linkage analysis and map construction}

A restriction fragment length polymorphism (RFLP)-based genetic linkage map was constructed using Mapmaker Version 3.0 (Lander et al., 1987) and marker scores for each DTP plant. All the markers were assigned to 10 linkage groups using a log of the odds ratio (LOD) score of 3.0 for all three-point and multipoint analyses. The Kosambi mapping function (Kosambi, 1944) was used to convert recombination fractions into genetic map distances $(\mathrm{cM})$. Linkage groups were determined using the "group" command and the marker order for each linkage group was determined using "first-order" command.

\section{QTL analysis}

QTL analysis was performed using QTL Cartographer (Basten et al., 1996) based on 
composite interval mapping (CIM). QTLs were declared present when the LOD score exceeded a threshold of 3.0. For each trait, multiple regression models were used to obtain the proportion of total phenotypic variance explained collectively by all QTLs identified for that trait under CIM. Analysis of variance was carried out using the general linear model procedure of the SAS program (SAS, 1998). Frequency distributions of the $\mathrm{F}_{2: 3}$ families for all traits were performed using the univariate procedure (PROC UNIVARIATE), and normality of distributions was checked using the Shapiro-Wilk test. Epistatic effects were estimated according to the definition of Mather and Jinks (1982). Pearson correlation coefficients $\left(\mathrm{R}^{2}\right)$ were calculated between traits using phenotypic means for each $\mathrm{F}_{2: 3}$ family.

\section{RESULTS}

\section{Phenotypic variation in drainpipe experiment}

Normality tests performed on the traits osmotic potential, leaf abscisic acid content, sugar concentration, relative water content, root density, root dry weight, total biomass, and leaf surface area showed that the frequency distributions of the $\mathrm{F}_{2: 3}$ families were normal (data not shown). The normality test was also carried out on grain yield under drought measured in the field, and distribution was found to be normal. The parental lines and the families were scored for the traits under the intermittent moisture deficit regime in the drainpipe set up. Significant differences were observed for all traits between parents and among $\mathrm{F}_{2: 3}$ families, which exhibited a wide range of variation for each of the traits. Transgressive segregants among the DTP population were also observed in both directions for most of the traits studied.

\section{Genetic mapping}

A total of 101 RFLP markers were assigned to one or the other of the 10 linkage groups of maize to construct the genetic linkage map (Figure 1). The selection of this set of the RFLP markers was based upon their relatively even distribution throughout the maize genome, which should allow any quantitative trait to be mapped. Other characteristics of these probes were their low copy numbers, which provided easy interpretation, and their high levels of polymorphism across a variety of maize germplasm. Using these markers, approximately $85 \%$ of the genome was mapped. With the exception of chromosome 8 , most regions of the maize genome were adequately represented.

\section{Detection and mapping of QTLs}

The relationship between molecular markers and drought-related traits was established using CIM and multiple regression analyses, where the markers were considered to be independent variables (Table 1). The associations were considered to be significant at $\mathrm{P}<$ 0.0001 , in which the coefficient of determination $\left(R^{2}\right)$ indicated the percentage of phenotypic variation explained by the marker genotypes at the locus. The QTLs for growth- and droughtrelated parameters in the drainpipe experiment and their relative positions were detected on maize chromosomes 1, 3, 6, 7, and 9 (Figure 2). QTLs for grain yield from the field trials were detected on chromosomes 1, 5 and 9 (Figure 2). 

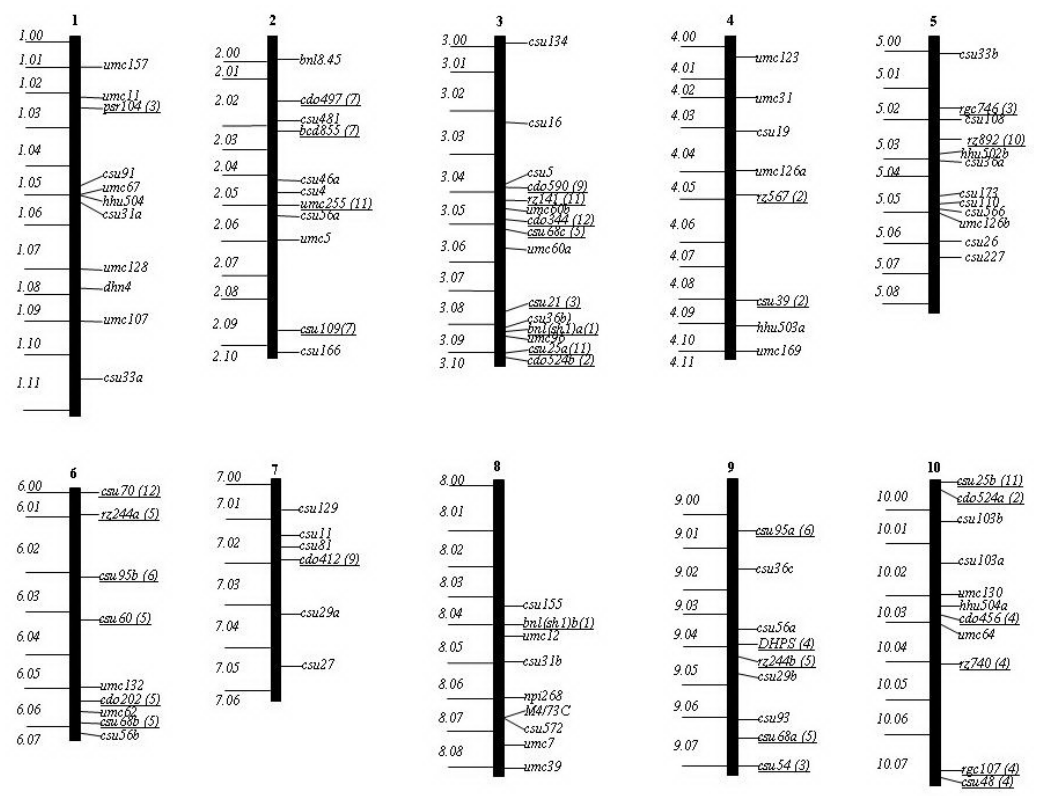

Figure 1. Genetic linkage map of maize chromosomes 1 through 10, with short arm toward the top. Symbols for loci are shown on the right side and are according to Gardiner et al. (1993). RFLP loci in bold and underlined on the right hand side of each chromosome represent probes mapped onto DTP x B73 that were also mapped onto the rice genome; chromosomal location of loci is on rice. The lines on the left of each chromosome represent UMC (University of MissouriColumbia) chromosome bin separators with bin numbers shown. Core bins shown on the left, spaced between core markers that delineate the boundaries for that bin, were labeled according to criteria described by Gardiner et al. (1993).

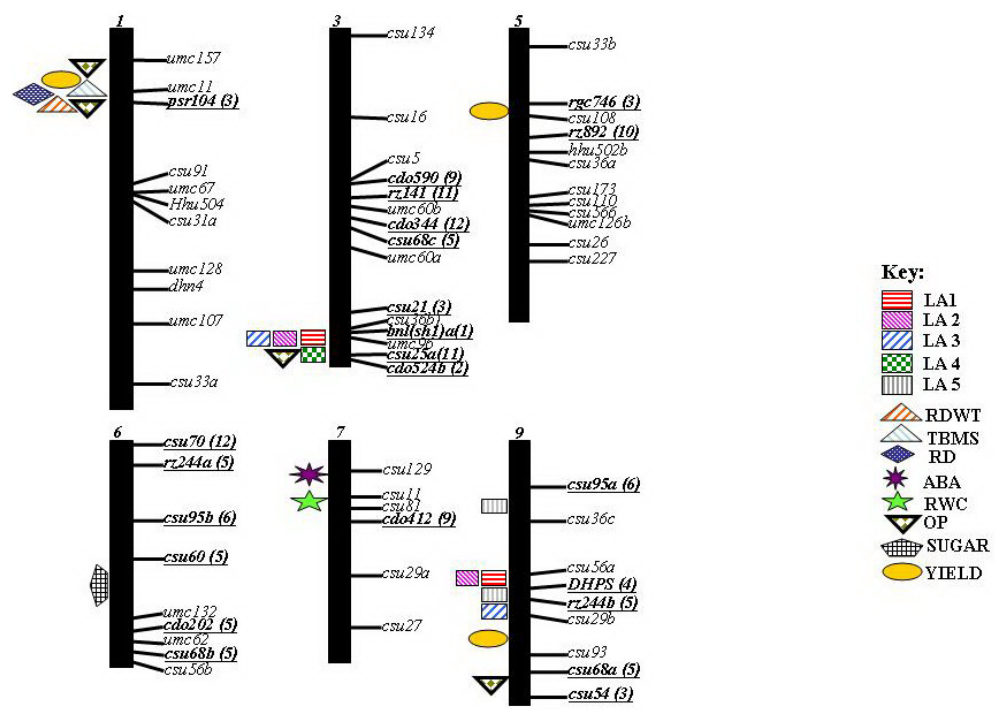

Figure 2. Estimated quantitative trait locus (QTL) position of drought-related parameters on maize chromosomes $1,3,5,6,7$, and 9. The positions of QTLs are shown on the left of the chromosomes, while the marker loci are on the right. For abbreviations, see legend to Table 1. 


\begin{tabular}{|c|c|c|c|c|c|}
\hline Trait & $\begin{array}{l}\text { Chromosomal } \\
\text { location }\end{array}$ & $\begin{array}{l}\text { Estimated QTL } \\
\text { position }\end{array}$ & $\begin{array}{c}\text { Additive } \\
\text { effect }\end{array}$ & $\begin{array}{c}\text { Dominance } \\
\text { effect }\end{array}$ & $\begin{array}{c}\mathrm{R}^{2}(\% \text { variance } \\
\text { explained by the QTL) }\end{array}$ \\
\hline SUGAR & 6 & csu60-umc132 & 0.59 & -0.38 & 52.2 \\
\hline$\overline{\mathrm{GY}}$ & $\begin{array}{l}1 \\
5 \\
9\end{array}$ & $\begin{array}{l}\text { umc157-psr104 } \\
\text { rgc746-csu108 } \\
\text { csu29b-csu93 }\end{array}$ & $\begin{array}{r}18.0 \\
-18.3 \\
-12.4\end{array}$ & $\begin{array}{r}2.4 \\
-1.9 \\
26.4\end{array}$ & $\begin{array}{l}14.0 \\
14.8 \\
46.2\end{array}$ \\
\hline$\overline{\mathrm{L}-\mathrm{ABA}}$ & 7 & csul29-csu81 & -144.8 & 15.3 & 19.0 \\
\hline$\overline{\mathrm{OP}}$ & $\begin{array}{l}1 \\
3 \\
9 \\
1\end{array}$ & $\begin{array}{l}\text { umc157-umc11 } \\
\text { umc96-csu25a } \\
\text { csu68a-csu54 } \\
\text { umc11-psr104 }\end{array}$ & $\begin{array}{r}-0.07 \\
0.04 \\
0.02 \\
-16.0\end{array}$ & $\begin{array}{c}-0.01 \\
-0.01 \\
-0.10 \\
6.0\end{array}$ & $\begin{array}{r}10.0 \\
7.0 \\
22.0 \\
11.0\end{array}$ \\
\hline$\overline{R W C}$ & 7 & csu11-csu81 & 0.03 & 0.01 & 7.0 \\
\hline$\overline{\mathrm{RD}}$ & 1 & umc157-psr104 & $\begin{array}{l}-0.78 \\
\end{array}$ & -0.22 & 24.2 \\
\hline RDWT & 1 & umc11-psr104 & -0.28 & -0.54 & 0.2 \\
\hline TBMS & 1 & umc11-psr104 & -0.74 & -0.88 & 0.4 \\
\hline$\overline{\mathrm{LA} 1}$ & $\begin{array}{l}3 \\
9 \\
\end{array}$ & $\begin{array}{l}\text { umc96-csu25a } \\
\text { csu56a-rz244b }\end{array}$ & $\begin{array}{r}-0.49 \\
0.92 \\
\end{array}$ & $\begin{array}{l}-0.45 \\
-0.20 \\
\end{array}$ & $\begin{array}{l}14.5 \\
27.7\end{array}$ \\
\hline$\overline{\mathrm{LA} 2}$ & $\begin{array}{l}3 \\
9 \\
\end{array}$ & $\begin{array}{l}\text { umc96-csu25a } \\
\text { csu56a-DHPS }\end{array}$ & $\begin{array}{r}-0.71 \\
1.54 \\
\end{array}$ & $\begin{array}{r}1.38 \\
-0.12 \\
\end{array}$ & $\begin{array}{l}15.7 \\
14.0\end{array}$ \\
\hline$\overline{\mathrm{LA} 3}$ & $\begin{array}{l}3 \\
9 \\
\end{array}$ & $\begin{array}{l}\text { umc } 96-c s u 25 a \\
\text { rz244b-csu29b }\end{array}$ & $\begin{array}{l}1.00 \\
3.96\end{array}$ & $\begin{array}{r}2.17 \\
-1.24 \\
\end{array}$ & $\begin{array}{r}5.0 \\
32.0 \\
\end{array}$ \\
\hline$\overline{\mathrm{LA} 4}$ & 3 & umc96-csu25a & 6.37 & -3.49 & 30.0 \\
\hline LA5LA5 & $\begin{array}{l}9 \\
9 \\
\end{array}$ & $\begin{array}{l}\text { DHPS -rz244b } \\
\text { csu95a-csu36c }\end{array}$ & $\begin{array}{l}6.17 \\
8.91\end{array}$ & $\begin{array}{l}-1.17 \\
-1.30\end{array}$ & $\begin{array}{r}9.2 \\
16.6 \\
\end{array}$ \\
\hline
\end{tabular}

SUGAR = sugar concentration; $\mathrm{GY}=$ grain yield under drought; $\mathrm{L}-\mathrm{ABA}=$ leaf abscisic acid content; $\mathrm{OP}=$ osmotic potential; $\mathrm{RWC}=$ relative water content; $\mathrm{RD}=$ root density; $\mathrm{RDWT}=$ root dry weight; TBMS = total biomass; $\mathrm{LA}=$ leaf surface area.

A total of 22 QTLs were detected with a minimum of one and a maximum of 9 for the traits under study (Table 1 and Figure 2). An important solitary QTL for sugar concentration (SUGAR) was identified and mapped on chromosome 6 between RFLP loci csu60 and umc132. A single QTL was identified for each of the traits: LA4 on chromosome 3 between umc 96 and csu25a; relative water content (RWC) on chromosome 7 between csu11 and csu81, and root density (RD), root dry weight (RDWT), and total biomass (TBMS) on chromosome 1 between RFLP loci umc157 and psr104, umc11 and psr104, and umc11 and psr104, respectively. Another single QTL was detected on chromosome 7 for L-ABA and RWC between csu129 and csu81 and csu11 and csu81, respectively. Two QTLs for each LA (LA1, LA2, LA3, and LA5) were identified on chromosomes 3 (between RFLP loci umc96 and csu25a) and chromosome 9 (between RFLP loci csu56a and rz244b, csu56a and DHPS, rz244ab and csu29b, DHPS and rz244b, and csu95a and csu36c). Three QTLs were detected for grain yield under drought. The most significant QTL for grain yield was predicted on chromosome 9 between RFLP loci csu29b and csu93 with two other QTLs of significant magnitude on chromosomes 1 and 5 in the genomic regions between umc 157 and psr104 and rgc 746 and csu108, respectively (Figure 2). Four QTLs were identified for osmotic potential on chromosomes 1, 3, and 9 between RFLP loci umc157 and psr104, umc1111 and psr104, umc96 and csu251, and csu68a and csu54, respectively (Table 1 and Figure 2).

The amount of phenotypic variance explained by each QTL varied considerably from trait to trait. Of these, the most significant was a solitary QTL for SUGAR, which accounted for about $52.2 \%$ of the phenotypic variance on chromosome 6. The 3 grain yield (GY) QTLs 
detected on chromosome 1, 5, and 9 together accounted for $75 \%$ of the phenotypic variation. A single QTL for L-ABA accounted for 19\%, whereas 4 QTLs for OP together explained 50\% of the phenotypic variance, respectively. A QTL for RWC contributed 7\% of the phenotypic variance on chromosome 7, while a single QTL for each of the traits RD, RDWT, and TBMS on chromosome 1 contributed to $24,0.2$ and $0.4 \%$ of phenotypic variance, respectively.

\section{Coincidence of QTLs}

Most QTLs were found in clusters on the chromosomes showing non-random distribution of genes in the genome. Four clusters of coincident QTLs were identified on chromosomes 1, 3, 7, and 9 (Figure 2). On chromosome 1, a QTL for yield was coincident with QTLs for several root traits (RDWT, RD), TBMS, and osmotic potential. The maximum likelihood locations for these QTLs were less than $15 \mathrm{cM}$ apart, between loci umc157 and psr104 (for distance, see Figure 1).

On the long arm of chromosome 3 (near telomeric end), QTLs for LA1, LA2, LA3, and LA4 were coincident with a QTL for OP with QTL maximum likelihood locations of 3.09 cM apart between umc96 and csu25a. The QTLs for leaf area were also clustered on chromosome 9 between csu56a and csu29b in a region of about $15 \mathrm{cM}$ (Figure 1). QTLs for L-ABA and RWC coincided on chromosome 7 in the region between loci csu129 and csu81 covering an area of about $10 \mathrm{cM}$. The lack of overlap or close association between QTL for OP and QTL for RWC, SUGAR, and L-ABA suggests that these physiological parameters are at least partly independent of each other.

\section{DISCUSSION}

Drought tolerance is among the complex traits assumed to be controlled by multiple genes under strong environmental influences. Such complex traits may be dissected as Mendelian factors with the application of molecular markers, which have emerged as a valuable tool to the arsenal of traditional plant breeding techniques. By establishing an association between a trait of interest and the molecular marker, screening for complex traits such as drought resistance can be considerably facilitated. We identified a number of QTLs for drought and its related traits in maize, which is an important cereal crop grown around the globe.

A genetic linkage map of the maize genome was developed by mapping 101 RFLP clones in $105 \mathrm{~F}_{2 \cdot 3}$ lines between a drought-tolerant and drought-susceptible cultivar of maize. The map indicates fair to good coverage of the genome. Maize embodies many of the features of a model genetic system. It has well-developed genetic maps, which encompass more than hundreds of genetic loci, including many expressed genes for several important traits (Coe et al., 1988; Gardiner et al., 1993). Being highly polymorphic, the maize genome offers greater opportunities for RFLP-based genetic mapping (Burr et al., 1988; Burr and Burr, 1991; Gardiner et al., 1993). Several maps are available in maize, of which the most prominent are still the RFLP maps. Helentjaris et al. (1986) constructed the first ever RFLP map in maize by pooling different data of F2 populations, which was later refined by Weber and Helentjaris (1989) using the B-A translocation system, which defined centeromeric regions of the maize chromosomes. During development of these maps, several duplicate loci were observed and mapped on maize chromosomes (Helentjaris et al., 1988). Recombinant inbred lines (Tx303 x C0159 and T232 x CM37) in maize were used to develop the 
segregating populations that were used to develop RFLP maps (Burr et al., 1988), utilizing averages of the recombination values as genetic distances. Agrigenetics Company has used two F2 populations and a recombinant inbred population (Murray et al., 1988) to develop another RFLP map in maize. In addition, comparative maps and a composite RFLP map based on pooled data sets and common markers from four F2 populations were developed (Beavis et al., 1991). RFLP maps in maize were also constructed using F2 immortalized (Hoisington and Coe, 1990) and immortalized populations (Gardiner et al., 1993). Genetic factors contributing to heterosis in hybrid maize were also identified (Stuber et al., 1992) using molecular markers. A comprehensive molecular map with sequenced core markers and a large number of ESTs is also available (Davis et al., 1999).

In the current study, we identified and mapped 22 QTLs for agronomic traits related to drought tolerance on maize genome, with a minimum of one QTL for all traits studied and as many as three for GY and 4 for OP. Clustering of QTL for LA2, LA3 and LA4 was evident on chromosome 3, while those for LA1, LA2 and LA3 coincided with GY in the same region of chromosome 9. Similarly, QTLs for RWC and leaf L-ABA content were coincident on chromosome 7. About $52 \%$ of the phenotypic variance was attributed to a single QTL for sugar concentration. Similarly, for GY, 3 QTLs were detected accounting for $75 \%$ of the phenotypic variation, while for L-ABA content and OP, 19 and 50\% of the phenotypic variation was attributable to 1 and 4 QTLs, respectively. The QTLs identified in this study allowed us to dissect and map drought-related traits at a finer level by partitioning genetic variation into components. The information obtained here may be useful for further improvement of maize against drought, one of the most important abiotic stresses of crop plants. Several other studies on QTL detection and analysis for drought and related traits under drought were conducted by a number of researchers. Agrama and Moussa (1996) detected 5 QTLs controlling grain yield under drought stress. A significant QTL in the same genomic region for yield (Quarrie et al., 1999) and drought resistance (Agrama and Moussa, 1996) has been reported to be located about $2 \mathrm{cM}$ from umc11 on chromosome 1, whereas 5 and 4 QTLs were detected for yield in tropical maize under intermediate and extreme stresses, respectively, under 3 irrigation regimes (Ribaut et al., 1997). In another study, 17 QTLs for yield components were identified (Frova et al., 1999), of which more than 50\% were detected under well-watered conditions.

The QTLs identified for RD and RDWT on chromosome 1 accounted for $25 \%$ of the phenotypic variance. Root traits play a significant role in GY under drought, and significant effects that were relevant to root traits at early stages were detected by Tuberosa et al. (2002b). Root size, morphology, depth, length, hydraulic conductance, and function are basics to meet the transpirational demands of the shoot (Passioura, 1982). Increased rooting density with extended root length enable plants to penetrate deeply and extract moisture from the deeper zones. An efficient root system can guarantee sufficient water availability for the plant from the deeper soil profile. Crop plants with large and deep root systems are believed to survive drought conditions much better than shallow and small root systems (Tuberosa et al., 2002a; Price et al., 2002; Bruce et al., 2002). Several studies have indicated that the ability of plants to regulate root system morphology in response to environmental cues can give a selective advantage (see review by Malamy, 2005). Fitz Gerald et al. (2006) studied the genetic and physiological complexity underlying root system size in Arabidopsis thaliana and dissected the molecular basis for variations in its morphology and developmental plasticity. Studies on root system size in Arabidopsis indicated a clear distinction between ecotypes Landsberg erecta and Columbia grown under mild conditions in response to drought (Meyre et al., 2001; Fitz Gerald et al., 2006). Osmotic adjustment, which is the active accumulation of solutes within the plant tissue in response to a decline in soil water potential, is another attribute of plants with drought tolerance potential (Morgan, 1995). A lower OP inside the plant tissue provides a driv- 
ing force for extracting water from low water potential sources.

Xiao et al. (2005) conducted a study on the QTL analysis of drought tolerance and yield in maize in China using SSR markers and mapped and characterized several QTLs for GY and yield components in the population developed from the cross X178 x B73 under water-stressed and well-watered conditions. Under the well-watered regime, 2, 4, 4, 1, 2, 2, and 3 QTLs were identified for GY, 100-kernel weight, kernel number per ear, cob weight per ear, kernel weight per ear, ear weight, and ear number per plant, respectively, whereas under the water-stressed conditions, 1, 5, 2, 6, 1, 3, and 2 QTLs, respectively, were found. The significant phenotypic correlations between yield and yield components were observed under both water conditions, and some overlaps between the corresponding QTLs were also found. QTLs for GY and kernel weight per ear under well-watered conditions and ear weight under both well-watered and water-stressed conditions overlapped, and all were located on chromosome 1.03 near marker bnlgl76. Qiu et al. (2007) identified and mapped 25 and 34 QTLs with effects ranging from 3.9 to $37.3 \%$. These QTLs were associated with water logging tolerance during the seedling stage in maize in 2 different experiments for a number of traits, including shoot dry weight, root dry weight, total dry weight, plant height, and their water-logging tolerance coefficients each mapped on chromosomes 4 and 9. These results were in greater agreement with our findings in the current study where we identified multiple QTLs for a single trait on different regions or on different chromosomes.

Conversely, the QTLs for multiple traits were found to be localized on a single chromosome or on segments of the chromosomal regions. Several overlapped QTL regions associated with yield and other traits were identified. A chromosomal region affecting GY, OP, and $\mathrm{RD}$ was located in the same marker interval (umc157-psrI04) on chromosome 1 (Table 1 and Figure 2). Another region in the markers interval between umc11 and psrI04 on chromosome 1 accounted for co-location of the QTLs affecting OP, RDWT, and TBMS. Overlap of QTLs for L-ABA concentration and RWC was detected on chromosome 7. This co-localization of QTLs for different traits implies the likely presence of pleiotropism or tight linkage between the QTLs that control the traits (Lebreton et al., 1995; Agrama and Moussa, 1996; Sanguineti et al., 1999; Tuberosa et al., 2002b; Xiao et al., 2005). In comparative analyses with previous studies, it was observed that several QTLs identified in the current study were common. These QTLs are more useful and will have greater potential in marker-assisted selection programs.

QTLs appear to be distributed throughout the genome with some regions harboring more than one drought-related parameter. The detected QTLs differed considerably in the magnitude of their effects. The lack of overlap between the QTL for osmotic potential and relative water content suggests that these two physiological parameters are at least partly independent of each other. The overlap observed between the QTL for osmotic potential, root density, total biomass, and grain yield is suggestive of genes with pleiotropic effects for these traits. QTL analysis using molecular markers can allow genetic dissection of traits of interest to partition genetic variation into its components and to study genetic associations among traits for pleiotropy and linkage relationships. Flanking markers of these major QTLs could help the breeder to select for these traits more effectively. Our findings reported here will assist plant breeders and geneticists to improve maize against drought.

\section{REFERENCES}

Agrama HAS and Moussa ME (1996). Mapping QTLs in breeding for drought tolerance in maize. Euphytica 91: 89-97. Ajmone MP, Monfredini G, Brandolini A, Melchinger AE, et al. (1996). Identification of QTL for grain yield in an elite 
hybrid of maize: repeatability of map position and effects in independent samples derived from the same population. Maydica 41: 49-57.

Austin DF and Lee M (1998). Detection of quantitative trait loci for grain yield and yield components in maize across generations in stress and nonstress environments. Crop Sci. 38: 1296-1308.

Babu RC, Nguyen BD, Chamarerk V, Shanmugasundaram P, et al. (2003). Genetic analysis of drought resistance in rice by molecular markers: association between secondary traits and field performance. Crop Sci. 43: 1457-1469.

Basten CJ, Weir BS and Zeng ZB (1996). QTL-Cartographer: a Suite of Programs for Mapping Quantitative Trait Loci. Plant and Animal Genome IV Conference, San Diego, 108.

Beavis WD, Grant D, Albertsen M and Fincher R (1991). Quantitative trait loci for plant height in four maize populations and their associations with qualitative genetic loci. Theor. Appl. Genet. 83: 141-145.

Bruce WB, Edmeades GO and Barker TC (2002). Molecular and physiological approaches to maize improvement for drought tolerance. J. Exp. Bot. 53: 13-25.

Burr B and Burr FA (1991). Recombinant inbreds for molecular mapping in maize: theoretical and practical considerations. Trends Genet. 7: 55-60.

Burr B, Burr FA, Thompson KH, Albertson MC, et al. (1988). Gene mapping with recombinant inbreds in maize. Genetics 118: 519-526.

Coe EH, Hoisington DA and Neuffer MG (1988). The Genetics of Corn (Sprague GF and Dudley IW, eds.). American Society of Agronomy, Madison.

Davis GL, McMullen MD, Baysdorfer C, Musket T, et al. (1999). A maize map standard with sequenced core markers, grass genome reference points and 932 expressed sequence tagged sites (ESTs) in a 1736-locus map. Genetics 152: 1137-1172.

Edwards MD, Stuber CW and Wendel JF (1987). Molecular-marker-facilitated investigations of quantitative-trait loci in maize: I. Numbers, genomic distribution and types of gene action. Genetics 116: 113-125.

Fitz Gerald JN, Lehti-Shiu MD, Ingram PA, Deak KI, et al. (2006). Identification of quantitative trait loci that regulate Arabidopsis root system size and plasticity. Genetics 172: 485-498.

Frova C, Krajewski P, Di Fonzo N, Villa M, et al. (1999). Genetic analysis of drought tolerance in maize by molecular markers I. Yield components. Theor. Appl. Genet. 99: 280-288.

Gardiner JM, Coe EH, Melia-Hancock S, Hoisington DA, et al. (1993). Development of a core RFLP map in maize using an immortalized F2 population. Genetics 134: 917-930.

Hallauer AR and Miranda JB (1989). Quantitative Genetics in Maize Breeding. 2nd edn. Iowa State University Press, Ames.

Hartung W and Davies WJ (1991). Drought-Induced Changes in Physiology and ABA. In: Abscisic-Acid: Physiology and Biochemistry (Davies WJ and Jones HG, eds.). Scientific Publishers Limited, Oxford, 63-80.

Helentjaris T, Slocum M, Wright S, Schaefer A, et al. (1986). Construction of genetic linkage maps in maize and tomato using restriction fragment length polymorphisms. Theor. Appl. Genet. 72: 761-769.

Helentjaris T, Weber D and Wright S (1988). Identification of the genomic locations of duplicate nucleotide sequences in maize by analysis of restriction fragment length polymorphisms. Genetics 118: 353-363.

Hoisington DA and Coe EH Jr (1990). Mapping in Maize Using RFLPs. In: Gene Manipulation in Plant Improvement (Gustafson JP, ed.). Plenum Press, New York, 331-352.

Kebede H, Subudhi PK, Rosenow DT and Nguyen HT (2001). Quantitative trait loci influencing drought tolerance in grain sorghum (Sorghum bicolor L. Moench). Theor. Appl. Genet. 103: 266-276.

Kosambi DD (1944). The estimation of the map from the recombination values. Ann. Eugen. 12: 172-175.

Kuraparthy V, Sood S, Dhaliwal HS, Chhuneja P, et al. (2007). Identification and mapping of a tiller inhibition gene (tin3) in wheat. Theor. Appl. Genet. 114: 285-294.

Lander ES, Green P, Abrahamson J, Barlow A, et al. (1987). MAPMAKER: an interactive computer package for constructing primary genetic linkage maps of experimental and natural populations. Genomics 1: 174-181.

Lebreton C, Lazic-Jancic V, Steed A, Pekic S, et al. (1995). Identification of QTL for drought responses in maize and their use in testing causal relationships between traits. J. Exp. Bot. 46: 853-865.

Li XH, Gao GL, Liang XL, Yuan LX, et al. (2002). Genetic diversity of drought tolerance at flowering time in elite maize germplasm. Acta Agron. Sin. 28: 595-600.

Malamy JE (2005). Intrinsic and environmental response pathways that regulate root system architecture. Plant Cell Environ. 28: 67-77.

Mather K and Jinks JL (1982). Biometrical Genetics. 3rd edn. Chapman and Hall, London.

Meyre D, Leonardi A, Brisson G and Vartanian N (2001). Drought-adaptive mechanisms involved in the escape/tolerance strategies of Arabidopsis Landsberg erecta and Columbia ecotypes and their F1 reciprocal progeny. J. Plant Physiol. 158: $1145-1152$.

Morgan JM (1995). Growth and yield of wheat lines with differing osmoregulative capacity at high soil water deficit in seasons of varying evaporative demand. Field Crops Res. 40: 143-152. 
Murray M, Cramer J, Ma Y, West D, et al. (1988). Agrigenetics maize RFLP linkage map. Maize Genet. Coop. Newsl. 62: 89-91.

Murray MG and Thompson WF (1980). Rapid isolation of high molecular weight plant DNA. Nucleic Acids Res. 8: 4321-4325.

Nelson N (1944). A photometric adaptation of the Somogyi method for the determination of glucose. J. Biol. Chem. 153: 375-380.

Passioura JB (1982). The Role of Root System Characteristics in the Drought Resistance of Crop Plants. In: Drought Resistance in Crops with Emphasis on Rice, Manila, 71-82.

Paterson AH, Lander ES, Hewitt JD, Peterson S, et al. (1988). Resolution of quantitative traits into Mendelian factors by using a complete linkage map of restriction fragment length polymorphisms. Nature 335: 721-726.

Price AH, Cairns JE, Horton P, Jones HG, et al. (2002). Linking drought-resistance mechanisms to drought avoidance in upland rice using a QTL approach: progress and new opportunities to integrate stomatal and mesophyll responses. J. Exp. Bot. 53: 989-1004.

Qiu F, Zheng Y, Zhang Z and Xu S (2007). Mapping of QTL associated with water-logging tolerance during the seedling stage in maize. Ann. Bot. 99: 1067-1081.

Quarrie SA (1991). Implications of Genetic Differences in ABA Accumulation for Crop Production. In: Abscisic Acid: Physiology and Biochemistry (Davies WJ and Jone HG, eds.). Bios Scientific Publishers, Oxford, 227-243.

Quarrie SA, Whitford PN, Appleford NEJ, Wang TL, et al. (1988). A monoclonal antibody to (S)-abscisic acid: its characterisation and use in a radioimmunoassay for measuring abscisic acid in crude extracts of cereal and lupin leaves. Planta 173: 330-339.

Quarrie SA, Lazic-Jacic V, Kovaccvic D, Steed A, et al. (1999). Bulk segregant analysis with molecular markers and its use for improving drought resistance in maize. J. Exptl. Bot. 50: 1299-1306.

Ribaut JM, Jiang C, Gonzalez-de-Leon D, Edmeades GO, et al. (1997). Identification of quantitative trait loci under drought conditions in tropical maize. II: Yield components and marker selection strategies. Theor. Appl. Genet. 94: 887-896.

Sanguineti MC, Tuberosa R, Landi P, Salvi S, et al. (1999). QTL analysis of drought-related traits and grain yield in relation to genetic variation for leaf abscisic acid concentration in field-grown maize. J. Exp. Bot. 50: 1289-1297.

Sari-Gorla M, Krajewski P, Di-Fonzo N, Villa M, et al. (1999). Genetic analysis of drought tolerance in maize by molecular markers. II. Plant height and flowering. Theor. Appl. Genet. 99: 289-295.

SAS I (1998). SAS Language Guide for Personal Computers. 6.03 edn. SAS, Cary.

Shah MM, Gill KS, Baenziger PS, Yen Y, et al. (1999). Molecular mapping of loci for agronomic traits on chromosome 3A of bread wheat. Crop Sci. 39: 1728-1732.

Sharp PJ, Kreis M, Shewry PR and Gale MD (1988). Location of $\beta$-amylase sequences in wheat and its relatives. Theor. Appl. Genet. 75: 286-290.

Singletary GW and Below FE (1990). Nitrogen-induced changes in the growth and metabolism of developing maize kernels grown in vitro. Plant Physiol. 92: 160-167.

Stuber CW, Lincoln SE, Wolff DW, Helentjaris T, et al. (1992). Identification of genetic factors contributing to heterosis in a hybrid from two elite maize inbred lines using molecular markers. Genetics 132: 823-839.

Thompson FB and Leyton L (1971). Method for measuring the leaf surface area of complex shoots. Nature 229: 572. DOI: $10.1038 / 229572 \mathrm{a} 0$.

Tuberosa R, Salvi S, Sanguineti MC, Landi P, et al. (2002a). Mapping QTLs regulating morpho-physiological traits and yield: case studies, shortcomings and perspectives in drought-stressed maize. Ann. Bot. 89: 941-963.

Tuberosa R, Sanguineti MC, Landi P, Giuliani MM, et al. (2002b). Identification of QTLs for root characteristics in maize grown in hydroponics and analysis of their overlap with QTLs for grain yield in the field at two water regimes. Plant Mol. Biol. 48: 697-712.

Tuberosa R, Salvi S, Sanguineti MC, Maccaferri M, et al. (2003). Searching for QTLs controlling root traits in maize: a critical appraisal. Plant Soil. 255: 35-54.

Weber D and Helentjaris T (1989). Mapping RFLP loci in maize using B-A translocations. Genetics 121: 583-590.

Xiao YN, Li XH, George ML, Li MS, et al. (2005). Quantitative trait locus analysis of drought tolerance and yield in maize in China. Plant Mol. Biol. Rep. 23: 155-165.

Yang DL, Jing RL, Chang XP and Li W (2007). Identification of quantitative trait loci and environmental interactions for accumulation and remobilization of water-soluble carbohydrates in wheat (Triticum aestivum L.) stems. Genetics 176: 571-584.

Zinselmeier C, Jeong BR and Boyer JS (1999). Starch and the control of kernel number in maize at low water potentials. Plant Physiol. 121: 25-36. 